\title{
Visualizing Chat Log Data Collected in 3-D Virtual Worlds
}

\author{
Katy Börner \& Yu-Chen Lin \\ Indiana University, SLIS \\ 10th Street \& Jordan Avenue, Main Library 019 \\ Bloomington, IN 47405 USA \\ E-mail: \{katy,yclin\}@indiana.edu
}

\begin{abstract}
The paper reports work in progress on the analysis and visualization of chat log data collected in 3-dimensional (3-D) virtual worlds. In particular, it presents an analysis and visualization of six log files containing chat utterances from 32 people that attended a demonstration of different learning environments in a 3-D virtual world. We start with an introduction and a review of research in 'social visualization'. Subsequently, we introduce the 3-D online browser technology used and present the analysis and discussion of chat log data. The paper concludes with a discussion and an outlook.
\end{abstract}

\section{Introduction}

Shared 3-D virtual worlds (VWs) differ from single user systems in that they equip their users with sophisticated self-representations called avatars (acting as placeholders for human users) that wave, dance, and share space. In addition, they facilitate natural, multi-perceptual interaction using spatial sound, animation, and video. The shared awareness of the environment provides users with a feeling of presence (Lombard \& Ditton, 1997) and an authentic context for interaction. It promotes informal communication - brief, unplanned, and frequent (Kraut et al., 1988) and makes users perceive VWs not as a system but as a place (Croon Fors \& Jakobsson, 2000) that frames interactive behavior (Harrison \& Dourish, 1996), and offers users the chance to interact with other people and engage in activities that have real consequences (Jakobsson, 1999; Dibbell, 1998). Accordingly, the research questions connected with the design and evaluation of 3-D collaborative VWs are manifold.

We believe that data mining and information visualization techniques (Card et al., 1999; Chen, 1999; Ware, 1999; Spence, 2000; Dodge \& Kitchin, 2000) can be advantageously applied to monitor, evaluate, and optimize collaborative 3-D VWs and to study their evolving communities. For example, they can be exploited to visualize general login data concerning the kind and length of the connection, navigation patterns, manipulation patterns, conversation patterns, or web access patterns.
This paper presents a visualization of six chat log files that contain utterances from 32 people logged into a 3-D virtual world. It starts with a review of literature on social visualizations. Subsequently, we introduce the 3-D online browser technology used to design the virtual world which we are studying. Next, we explain and discuss different visualizations of chat log files. The paper concludes with a discussion and an outlook.

\section{Social visualizations}

Social visualizations show data about a person, illuminate relationships among people, or aim to visualize user group activity. For example, lifeline visualizations are used for revealing migrations, transitions and trajectories (Kullberg, 1995; Plaisant et al., 1996). Other research aims at the visualization of very large-scale conversations such as those that take place on the Usenet (Smith, 1998; Donath et al., 1999; Paolillo, 2000; Sack, 2000) or visualize web activity or user trails (Skog \& Holmquist, 2000; Wexelblatt, 1999; Minar, 1999; Hochheiser \& Shneiderman, 1999). The representation of people in text-based or graphical VWs by avatars is yet another topic. Avatars are varied and range from purely textual descriptions over 2-D smiley faces, cartoon characters or photographic images, to abstract or highly realistic 3-D models (Damer, 1997).

Further, there is interest in visualizing and supporting social interactions in text-based or 2-D graphical systems (Donath, 1995; Erickson et al., 1999). Chat Circles (Donath et al., 1999) is a 2-D graphical interface for synchronous conversation. It visualizes the non-textual components of online chatting such as pauses and turn-taking behavior, that can be key to fully understanding the nature of discussion (Saville-Troike, 1982) and that are lost in regular chat log files. The conversational archive of Chat Circles can be visualized as a 2-D, interactive conversational landscape in which each vertical line shows the activity of one participant and the horizontal lines are postings. PeopleGarden (Xiong \& Donath, 1999) uses a particularly apt flower metaphor to create individual data portraits of chat participants and a garden metaphor for combining these portraits to present the conversation activity of a group of participants. 
Another line of research aims at the visualization of MUDs or 3-D virtual worlds themselves in the form of 2-D or 3-D spatial maps. Martin Dodge's Atlas of Cyberspaces section on MUDs \& Virtual Worlds (Dodge, 2000) gives a good overview. Maps by Andrew Smith (2000) even show the urban density and the teleport systems of his 3-D world.

The existing systems teach many valuable lessons about how to visualize online spaces, their users, navigation and conversation activity, as well as (social) relationships. However, the analysis of computer-mediated communication is dominated by textual analysis without spatial reference, using linguistic discourse analysis and ethnographic methods (Herring, 1996). To our knowledge, there exists no analysis of simultaneously generated chat $\log$ files recorded in a 3-D world.

This paper reports first results of such an analysis and its visualization. In addition, it points out productive directions for the application of information visualizations that would benefit the design, evaluation, and optimization of 3-D VWs.

\section{Designing 3-D collaborative virtual worlds}

Different commercial 3-D Online Browser Systems are available to design collaborative virtual worlds (VWs) that are accessible from standard computer platforms via the Internet, 24/7. Frequently used systems are Blaxxun's online community client-server architecture (http://www.blaxxun.com/community), Microsoft's Virtual Worlds Platform (http://www.vworlds.org/), Active Worlds technology by Activeworlds.com, Inc. (http://www.activeworlds.com/), or the new Atmosphere browser (http://www.adobe.com/products/atmosphere/) by Adobe. Damer (1997) provides a review of different systems and existing virtual communities. To appreciate the potential of 3-D browser systems one has to try them out for oneself.

Each of the above listed 3-D browser systems facilitates the creation of multi-modal, multi-user, navigable, and collaborative VWs in 3-D that are interconnected with standard web pages. All represent users by avatars, providing an authentic means of interacting with objects in the 3-D VW, with embedded information sources and services, or with other users. In all these systems, users can communicate synchronously via a chat facility or a real-voice audio connection.

The selection of the appropriate browser system is critical since the technology that mediates user interaction has a great impact on the forms that interaction will take (Jakobsson, 1999; Preece, 2000).

Active Worlds (AW) is one of the most popular VW systems. Figure 1 shows the AW interface. In contains three main windows: a 3-D graphics window populated by avatars, a web browser window, and a chat window. At the top are a menu bar and a toolbar for avatar actions.

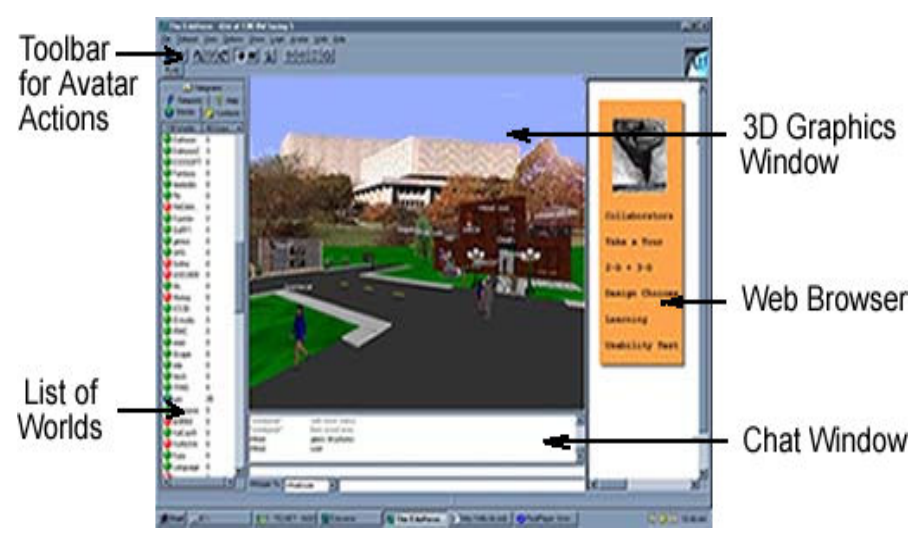

Figure 1. The 3-D AW interface

Users can collaboratively navigate in 3-D, move their mouse pointer over an object to bring up its description, click on 3-D objects to display the corresponding web page in the right web frame of the AW browser, or teleport to other places. The web browser maintains a history of visited places and web pages so that the user can return to previous locations.

Currently, AW hosts over six hundred different worlds in the main, entertainment oriented universe, and more than one hundred worlds in EduVerse, a special universe with an educational focus.

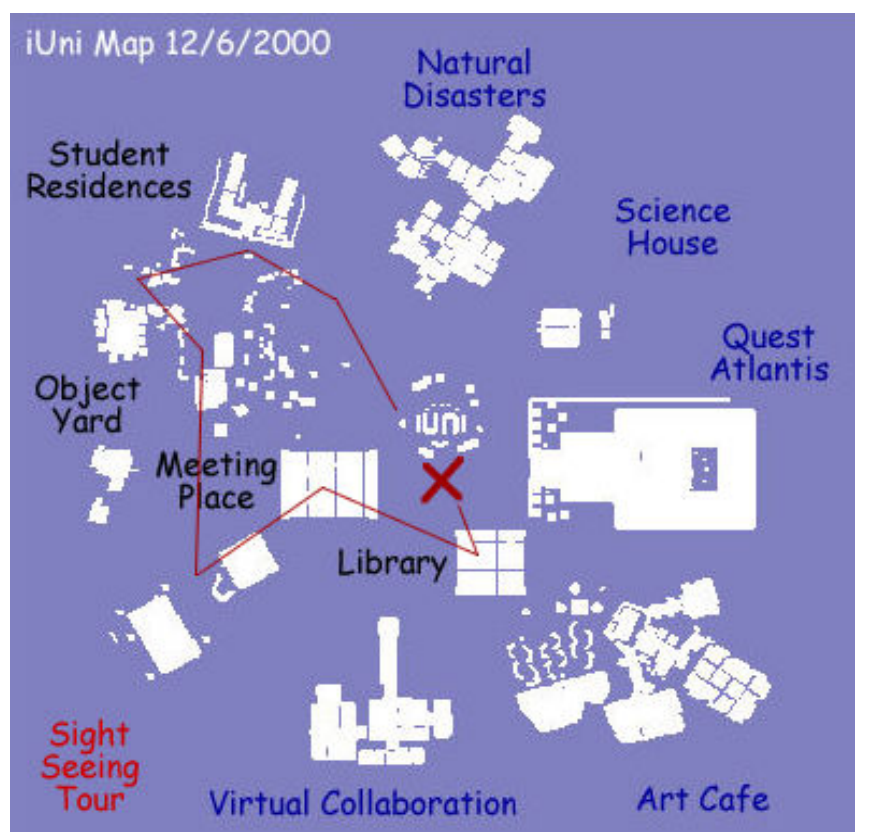

Figure 2. A 2-D overview map of iUni 


\begin{tabular}{|c|c|c|}
\hline Katy: Hi everybody! & Brian: Good morning! & Kent: Morning \\
\hline meow: hi, katy. & Katy: Hi Mite! & Katy: Where are your from \\
\hline mite2a: Hi, everybody & mite2a: Hong Kong time is 11 & Mite? \\
\hline Brian: Good morning! & p.m.Brian: (to mite2a) Good & Hello: hello \\
\hline Katy: Hi Mite! & evening & mite2a: Hong Kong. \\
\hline Kent: Morning & mite2a: Good evening to you. & Wired: ok \\
\hline Katy: Where are your from & Do you have to get prepared for & Katy: Hi Niki! \\
\hline Mite? & the presentation. I hope I have & Wired: I've been here beofre \\
\hline$\overline{\text { Hello: hello }}$ & not been causing you any & Hello: a lot of stuff to load up \\
\hline mite2a: Hong Kong. & problem. & Willo: let's go on the tour first \\
\hline Wired: ok & Kent: Morning & Katy: Hello hello! \\
\hline Katy: Hi Niki! & Brian: (to mite2a) not at all & Niki: hi \\
\hline Wired: I've been here beofre & Katy: Where are your from & Katy: Where is hello from? \\
\hline Hello: a lot of stuff to load up & Mite? & Cloud: ok \\
\hline Willo: let's go on the tour first & Hello: hello & Willo: come n \\
\hline Katy: Hello hello! & mite2a: Hong Kong. & Willo: on \\
\hline Niki: hi & Wired: ok & Willo: that is \\
\hline Katy: Where is hello from? & Katy: Hi Niki! & Katy: WE WILL START THE \\
\hline Cloud: ok & Wired: I've been here beofre & DEMO IN 10 MINs \\
\hline Willo: come n & Hello: a lot of stuff to load up & $\overline{\text { Cloud: I"m waiting }}$ \\
\hline Willo: on & Willo: let's go on the tour first & Bernie: hello cloud \\
\hline Willo: that is & Katy: Hello hello! & Cloud: hey \\
\hline$\overline{\text { Hello: I came to tour here }}$ & Niki: hi & Willo: I'm trying to figure that \\
\hline Katy: WE WILL START & Katy: Where is hello from? & out \\
\hline THE DEMO IN 10 MINs & Cloud: ok & \\
\hline
\end{tabular}

Figure 3. Top most utterances in three chat log files

The iUni - Information Universe (Börner, 2001) - is a world in EduVerse. Figure 2 shows an overview map of the $400 \mathrm{~m}$ by $400 \mathrm{~m}$ area of the iUni world rendered in 2$\mathrm{D}$ based on the list of objects that made up the world on Dec $6^{\text {th }}, 2000$. Objects are rendered in white. Black labels are used to identify community spaces. The learning environments are labeled in blue.

On Dec. 7, 2000, 10am-noon, iUni was demonstrated to 32 users logged in from all over the world, including sites in the US, Liverpool, and Hong Kong. The demo started with a short introduction of the world followed by a sight-seeing tour (denoted in red in Fig. 2) of student residences and community places. Subsequently, students showed and explained five different learning environments - a Natural Disaster Area, a Science House, a Quest Atlantis portal to different theme parks for kids, an Art Cafe, and a Virtual Collaboration area that they had created in collaboration with faculty at Indiana University. The 3-D VW graphics window in Fig. 1 shows the Natural Disaster area in the iUni world, which teaches about the formation and effects of tornadoes. See http://ella.slis.indiana.edu/ katy/iUni/ for details.

During the demo, the AW chat window was used to guide participants and to answer questions. After the demonstration, chat logs were collected from six users. The logs report the chat utterances of the user plus the avatars that are in closest proximity - maximally at a $120 \mathrm{~m}$ distance. Figure 3 shows the top lines of three chat log files collected by users 'Katy', 'Brian', and 'Kent'. Utterances that show up in more than one log file are underlined. Utterances which have been whispered to another user such as 'Brian: (to mite2a) Good evening' are logged in the whisperer's chat file and contain the recipient of the chat message in parenthesis.

\section{Chat log file analysis}

The chat log files have been analyzed to answer questions such as: How many users participated in the discussion surrounding the demo as logged in the chat files? How much overlap exists among the log files? How much do users chat and who chatted the most? How many utterances are devoted to greeting, explanation, commands, questions, or other topics? How long is the average utterance length (number of words in a utterance) for different users? How often do users whisper? The results are presented subsequently.

Altogether, the 6 chat log files contain utterances of 32 users (7 visitors and 25 EduVerse citizens). Figure 4 plots the virtual names of all users on the $x$-axis (see Fig. 5 for a close-up). Names in quotes such as "Diane" indicate users with visitor status. All other users are 'citizens' of the EduVerse. The y-axis indicates the number of unique (dark/red) and duplicate (gray) utterances as they appear in the different chat log files. Blue dots on top of bars indicate the users that provided 
the chat $\log$ files and thus users for which we have a complete record of chat activity.

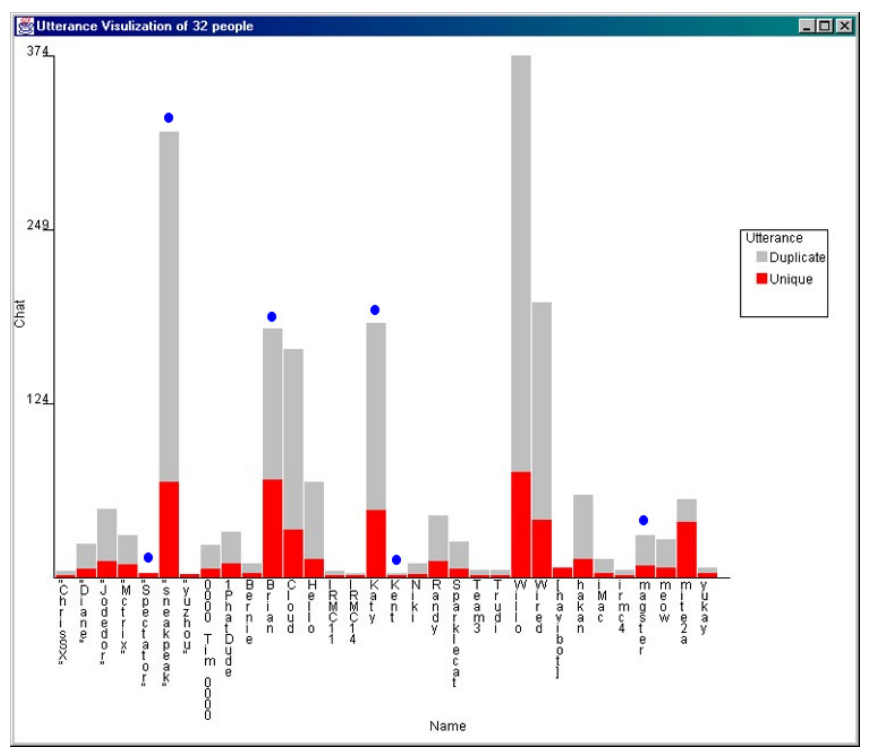

Figure 4. Unique and duplicate chat utterances

According to Fig. 4 there are seven users who actively participated in the discussion with more than 25 utterances. Two of them - "sneakpeak" and 'Willo' have a large number of duplicated utterances, indicating that they stayed in close range to the users from which the chat log files were collected.

Subsequently, each unique chat utterance has been semi-automatically classified into one of five categories. These categories together with the number of utterances in each category as well as sample utterances are as follows:

$\begin{array}{lll}\text { No } & \text { Category } & \text { Sample Utterances } \\ 49 & \text { Greeting } & \text { hello | Hi | Bye } \\ 214 & \text { Explanation } & \text { North | teachers here at IU } \\ 21 & \text { Command } & \text { Go to sign | See web page right | } \\ \text { Click } & & \\ 59 & \text { Question } & \text { Can you access the WebCast? } \\ 159 & \text { Other } & \text { lol | ok | cool }\end{array}$

Note that 'Commands' start with a verb and advise certain actions. Utterances classified as 'Other' are typically short.

Figure 5 shows the number, lengths, and type of unique chat utterances resembling the (dark/red) bars in Fig. 4. Each utterance is represented by a rectangle of uniform height. The width of the rectangle corresponds to the number of more or less meaningful 'words' in the utterance. The color of the rectangle reflects its type according to the five categories. Ovals denote that the utterance was whispered.

The visualization reveals that some people such as 'yukay' posed questions exclusively. Others, such as 'Randy' specialized in long explanations. 'Willo' very actively participated in the chat discussion. However, most of the utterances get classified under 'Other'. The 'Brian', 'Katy', and "sneakpeak" accounts were used to give the demo while specific learning environments were presented by '000 Tim 000', 'Randy', 'hakan', and 'magster'. This is correctly reflected in Fig. 5.

Colored, full-size versions of Figures 2, 4, and 5 are accessible at http://ella.slis.indiana.edu/ katy/IV2001a.

\section{Discussion \& outlook}

The presented analysis shows that chat log files concurrently recorded in a 3-D VW can be analyzed to answer questions concerning number, length, and topic of recorded utterances. However, the chat log data gives very limited insight into the 3 -D interaction that took place between the different users. A major problem is the restricted range of chat logging in the AW browser. If people from which chat log files are taken are close in space, then the union of their chat ranges does not cover the entire virtual world and the log file misses chat that takes place at remote locations.

Given that participants move around in a 3-D space, the set of users in chat range is constantly changing too. Assuming that users try to stay close to one another and visit different places together, chances are high that most of the chat was captured during the demonstration of iUni. However, in general, and especially for less organized events, it would be desirable to record all chat utterances by utilizing bots (software programs) positioned in a grid like fashion throughout the 3-D space.

Furthermore, the chat log files contain no information on the 3-D position of the users' avatar nor any kind of time stamp that would allow one to plot and relate utterances of different users in 3-D space and time. This information seems to be important in analyzing humanhuman and human-computer interaction and needs to be recorded in order to analytically examine and evaluate virtual worlds and their communities.

Besides having a chat log file in which each utterance is saved with a 3-D position, and a time stamp, it would be desirable to $\log$ the 3-D position of each user in the 3D VW continuously. 


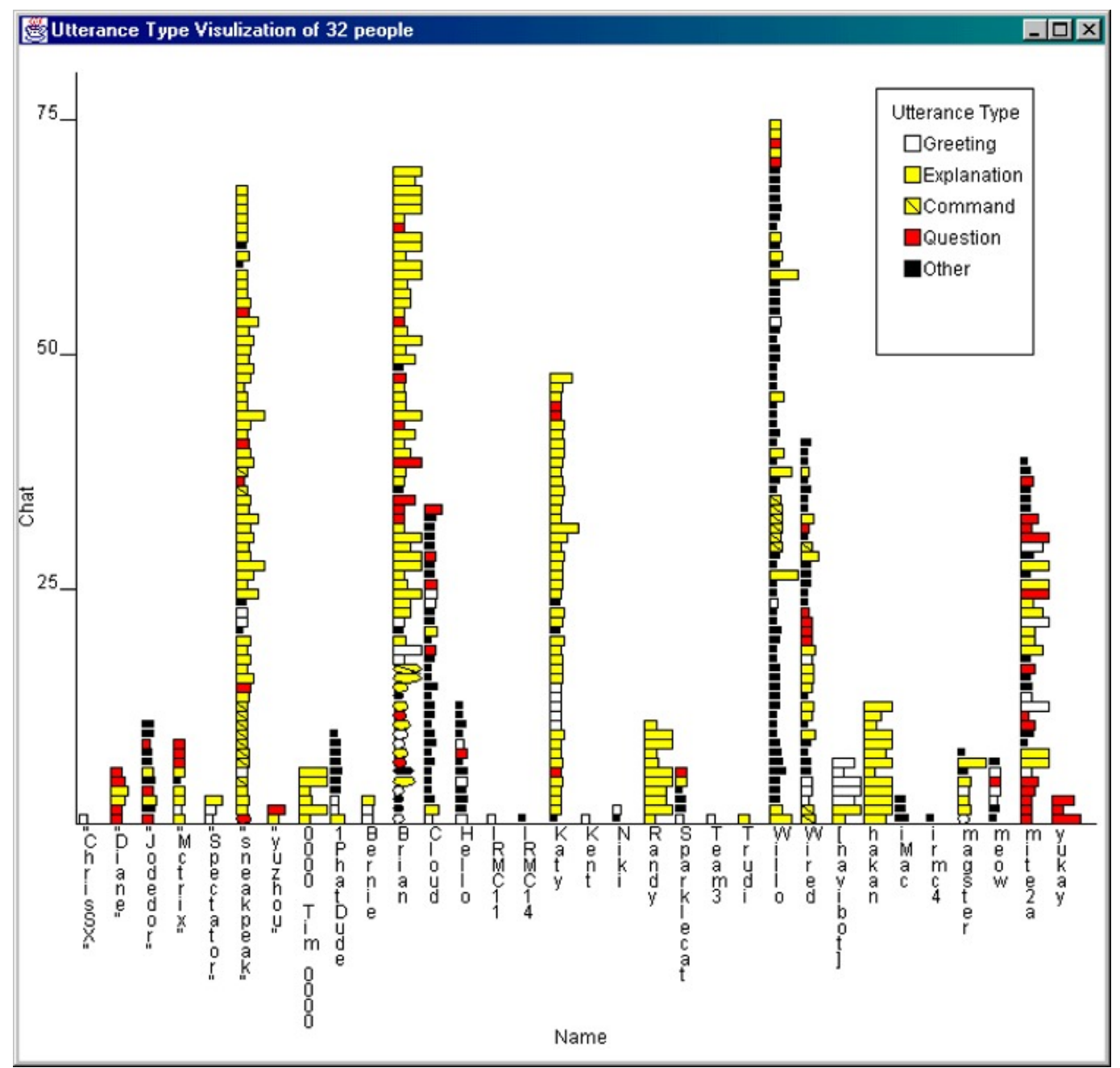

Figure 5. Number, lengths and type of unique chat utterances

This would help to reveal 'lurkers' - users that may have followed the demo but did not contribute to the conversation at all. While their avatars may have been visible to other users during the demo, the information captured in the log file does not reveal them.

Last but not least, user interaction in VWs comprises not only chat but also navigation (e.g., teleport usage) and manipulation (e.g. web access) activity. These activities need to be recorded as well if they are to be visualized and evaluated. Our future research will aim to develop tools that permit one to record, analyze, and interactively explore user behavior in 3-D VWs. The resulting visualizations are intended to aid designers with the organization and layout of world content and the selection of interaction possibilities, to assist users in making sense of the world, its information resources, and collaboration possibilities, and to enable researchers to study the communities evolving in 3-D VWs.

\section{Acknowledgements}

We acknowledge ActiveWorld's generous support in providing free hosting of 3-D VWs for educational purposes as well as an active research environment in EduVerse. Several students are involved in this research including Sy-Miaw Lin, Maggie Swan, and Min Xiao. The research is supported by a High Performance Network Application grant from Indiana University 2000/2001.

\section{References}

Börner, K. (2001) Using Active Worlds Technology to build an iUniverse of 3-D collaborative learning environments. IEEE Learning Technology newsletter. January.

Card, S. K., MacKinlay, J. D., Shneiderman B. (Editors) (1999) Readings in Information Visualization: Using Vision to Think, Morgan Kaufmann Publishers.

Chen, C. (1999) Information Visualisation and Virtual Environments. Springer Verlag. 
Croon Fors, A. \& Jakobsson, M. (2000) Beyond use and design - The dialectics of being in virtual worlds. Internet Research 1.0: The state of the interdiscipline. Lawrence, KS, USA.

Damer, B. (1997) Avatars!: Exploring and Building Virtual Worlds on the Internet. Peachpit Press.

Dibbell, J. (1998) My tiny life. Crime and passion in a virtual world, Henry Holt \& Co, New York.

Dodge, M. \& Kitchin, R. (2000) Mapping Cyberspace. Routledge.Damer, B. (1997) Avatars!: Exploring and Building Virtual Worlds on the Internet. Peachpit Press.

Dodge, M. (2000) An Atlas of Cyberspaces. Multi-User Dimensions (MUDs) \& Virtual Worlds http://www.geog.ucl.ac.uk/casa/martin/atlas/muds vw.html

Donath, J. (1995) Visual Who: Animating the affinities and activities of an electronic community. ACM Multimedia 95 Electronic Proceedings. San Francisco, California

Donath, J., Karahalios, K. \& Viegas, F. (1999) Visualizing conversation. Journal of Computer Mediated Communication, 4(4). http://www.ascucs.org/jcmc/vol4/issue4/donath.html

Erickson, Th., Smith, D. N., Kellogg, W. A., Laff, M., Richards, J. T. \& Bradner, E. (1999) Socially Translucent Systems: Social Proxies, Persistent Conversation, and the Design of "Babble", Proceeding of the CHI 99, pages $72-79$.

Harrison, S. \& Dourish, P. (1996) Re-place-ing space: the roles of place and space in collaborative systems. Proceedings of the ACM 1996 Conference on Computer Supported Cooperative Work, pages 67 - 76.

Herring, S. C. (ed) (1996) Computer mediated communication. Linguistic, social and cross-cultural perspectives. John Benjamins Pub Co., Amsterdam/Philadelphia.

Hochheiser, H. \& Shneiderman, B. (1999) Using interactive visualizations of www log data to characterize access patterns and inform site design. ftp://ftp.cs.umd.edu/pub/hcil/Reports-AbstractsBibliography/pdf/99-30.pdf.

Holmström, H. \& Jakobsson, M. (2001). Using models in virtual worlds design. Proceedings of the 34th Annual Hawaii International Conference on Systems Sciences, Los Alamitos, CA: Institute of Electrical and Electronics Engineers (IEEE) Computer Society.

Jakobsson, M. (1999). Why Bill was killed - understanding social interaction in virtual worlds. In Nijholt, A. et al. (eds.). Interactions in virtual worlds. Proceedings of the fifteenth Twente workshop on language technology. Enschede, The Netherlands: Twente University.

Kim, A. J. (2000) Community Building on the Web: Secret Strategies for Successful Online Communities, Peachpit Press.

Kraut, R., Galegher, J. \& Egido, C. (1988) Tasks and relationships in scientific research collaborations. HumanComputer Interaction, 3, 31-58.

Kullberg, R. L. (1995) Dynamic Timelines: Visualizing Historical Information in Three Dimensions. M.S. Thesis at the MIT Media Laboratory (Boston, MA, September 1995).

Minar, N. (1999) Visualizing the crowds at a web site. Extended abstracts of the CHI 99 Conference on Human Factors in Computing Systems.

Paolillo, J. C. (2000) Visualizing Usenet: A Factor-Analytic Approach. Proceedings of the $34^{\text {th }}$ Annual Hawaii International Conference on Systems Sciences, Los
Alamitos, CA: Institute of Electrical and Electronics Engineers (IEEE) Computer Society.

Plaisant, C., Milash, B., Rose, A., Widoff, S. \& Shneiderman, B. (1996) Life Lines: Visualizing personal histories. ACM CHI '96 Conference Proceedings, 221-227.

Preece, J. (2000) Online Communities: Designing Usability and Supporting Sociability. John Wiley \& Sons.

Sack, W. (2000) Discourse Diagrams: Interface Design for Very Large Scale Conversations. Proceedings of the $34^{\text {th }}$ Annual Hawaii International Conference on Systems Sciences, Persistent Conversations Track, Los Alamitos, CA: Institute of Electrical and Electronics Engineers (IEEE) Computer Society.

Saville-Troike, M. (1982) The Ethnography of Communication. 2nd Edition. New York, NY: Basil Blackwell.

Schvaneveldt, R. (Editor) (1990) Pathfinder Associative Networks: Studies in Knowledge Organization. Norwood, NJ: Ablex.

Shneiderman, B. (2000) Creating creativity: User interfaces for supporting innovation. ACM Transactions on ComputerHuman Interaction Vol 7, Issue 1, pp. 114-138.

Skog, T. \& Holmquist, L.E. (2000) WebAware: Continuous visualization of Web site activity in a public space. Proceeding of the CHI 2000 Conference on Human Factors in Computing Systems, pages 351-352.

Smith, A. (2000) Mapping 30 days, CASA, http://www.casa.ucl.ac.uk/30days/mapping.htm

Smith, M. (1998) Invisible Crowds in Cyberspace: Measuring and Mapping the Social Structure of USENET in Communities in Cyberspace: Perspectives on New Forms of Social Organization by Smith, M. and Kollock, P., Routledge Press.

Spence, R. (2000) Information Visualization. Addison-Wesley.

Ware, C. (1999) Information Visualization: Perception for Design, Morgan Kaufmann Publishers.

Wexelblat, A. (1999) History-Based Tools for Navigation Proceedings of the $32^{\text {nd }}$ Annual Hawaii International Conference on Systems Sciences, Los Alamitos, CA: Institute of Electrical and Electronics Engineers (IEEE) Computer Society.

Xiong, R. \& Donath, J. (1999) PeopleGarden: Creating data portraits for users. Proceedings of the 12th annual ACM Symposium on User Interface Software and Technology, pages $37-44$. 